Becoming Australian: A Review of Southern Sudanese Educational Experiences

First author: Dr Maura Sellars

University of Newcastle, NSW Australia

School of Education

Maura.Sellars@newcastle.edu.au

Co Author: Dr Helen Murphy

University of East London, UK

School of Psychology

h.murphy@uel.ac.uk 


\section{Becoming Australian: A Review of Southern Sudanese Educational Experiences}

\section{Abstract}

This writing presents a retrospective view of the literature around meeting students' learning needs in Australian schools. It has particular reference to one particular group of students with refugee experience who have been in Australian schools for over a dozen years; students with a background of oracy from Southern Sudan. It highlights the complexities and challenges of the Australian education system in their attempts to authentically engage with the psychological and literacy needs of these students. The development of psychological health and literacy competencies are considered to be two of the most critical and complex responsibilities undertaken by education, and, in the case of these students two of the most significant when considered in relation to successful settlement, acculturation and assimilation. In presenting this literature, the bigger picture of how schools can fail, not only these particular students, but for any number of students from diverse backgrounds, becomes startlingly obvious, as do the ways in which in which the current political agenda inherent in the public education system in Australia privileges students of specific class and culture. Finally, recommendations are made regarding the development of policy and the concentration on pedagogical practices which acknowledge and respect the strengths and capabilities of this group of students with refugee experiences and of all the diverse student cohorts who are currently engaging with Australian schooling.

Introduction

As the world becomes continuous disrupted by famine, war and the subsequent need for entire populations to flee their homelands in search of a more settled, fulfilling life elsewhere on the globe, a significant disruption to cultural ways of knowing and doing also takes place. Differences in beliefs, values and epistemological understandings become evident as many countries, including Australia, strive to provide new homelands and opportunities for these populations, despite the considerable differences in some aspects of daily life; including education. The purpose of this study is to critically review the literature relating to the students with refugee experiences who arrived to settle in Australia from Southern Sudan since 2002. The literature reflects the provision that was made by the Australian education systems to accommodate these students, both in terms of their English literacy and their wellbeing. Some background is provided to illustrate the ways in which the global diaspora is impacting on the world's communities, especially in terms of the experiences that students from these backgrounds endure prior to settlement in their new home countries and in terms of the sheer magnitude of the populations involved in these displacements.

\section{Global diasporas and the refugee experience}

Recently, forced migration has led 42 million people leaving their home country, including 26 million internally displaced persons ${ }^{1}$ (IDPs, United Nations Development Program (2009) and 15.2 million

\footnotetext{
${ }^{1}$ IDPs become displaced in their own countries usually as a result of natural disasters, armed conflict, or human rights violations. IDPs remain under the legal protection of their own government (see http://www.unhcr.org/pages/49c3646c146.html)
} 
refugees $^{2}$. According to the UNHCR 2009 figures, 44\% of these refugees and asylum seekers ${ }^{3}$ were minors. In contrast to voluntary/economic migrants, the needs of internally displaced persons, refugees and asylum seekers are not comparable according to the United Nations Development Program (UNDP) (UNDP, 2009). Currently, the global diaspora is accelerating at such an alarming rate that it is almost impossible to keep track of numbers and to gather statistics that are valid for any length of time. Forced migrants are vulnerable in systems that exploit their economic and personal vulnerability. Compared to other populations in large resettlement countries, G. ??? Davidson, Murray, and Schweitzer (2008), found that refugees have poorer general health; poorer mental health including increased somatisation and dissociation; increased levels of psychological distress including susceptibility to posttraumatic stress disorder (PTSD), anxiety and depression; impairments in cognitive function; low perceptions of educational achievement and career aspirations; a lack of family cohesion and reduced feelings of belonging.

Social inequalities experienced by refugees and asylum seekers may be a result of government legislation that produce embargos on paid work, economic markets that exploit cheap labour and social benefit systems that house inequality and bias (Ghosh, 2005; Sales, 1992). G. Davidson and Carr (2010) argue further that forced migration is inextricably linked to social exclusion and poverty and that individuals from refugee backgrounds find themselves in the midst of governmental systems that offer them little social and economic capital. Child asylum seekers and child refugees are an especially vulnerable grouping in the global diaspora. Chronic ill health was more common in child asylum seekers and the authors concluded that this particular group of children were both income and asset poor and at considerable disadvantage compared to children from the home nation.

Indicative of the fast pace of change that is happening both globally and in the Australian context, both past and recent global unrest has created an influx of people from various parts of the world into Australia. These populations impacted on society, culture, and education. While the degree (or lack thereof) of change to the nature of Australian culture and society is matter for further discussion, there is strong evidence that indicates that Australian education is still operating from the perspective of the British colonial perspective (Bird, 1995). It appears that what has been learned about educating students from backgrounds of oracy has had little impact on the bigger picture of educational policy. The previous 225+ years of 'educational' interactions with the original owners of the land; Aboriginal and Torres Strait Islander peoples. The dominant 'way of knowing' reflected in Australian curriculum, apart from minimal references to the inclusion of other cultural knowledge, is the white, middle class, British perspective on the world, which is presented as the discourse of power. The current climate of economic rationalism has only served to narrow this view, and, despite the essentially complex nature of the skills that current students will need to become productive members of Australian society and contribute meaningfully to

\footnotetext{
${ }^{2}$ Refugees leave their home country as result of fear of persecution for reasons of race, religion, nationality, political opinion or membership of a particular social group (see http://www.unhcr.org/pages/49c3646c125.html)

${ }^{3}$ Individuals who have fled their countries usually as a result of fear of persecution for reasons of race, religion, nationality, political opinion or membership of a particular social group and seek asylum elsewhere (see http://www.unhcr.org/pages/49c3646c137.html)
} 
its economic growth and wellbeing, have resulted in an increasingly restrictive curriculum and pedagogy for all students, including those from vastly different epistemological backgrounds.

\section{The promise of a land down under: coming to Australia as a Sudanese refugee}

Sudan has the second largest number of people in the world leaving their country as refugees (UNHCR, 2008) and because of the conflict and genocide the country has experienced is considered one of the worst humanitarian situations in the world (Milner \& Khawaja, 2010). In 2015, the Global Peace Index (Institute for Economics and Peace, 2015) ranked levels of safety and security, extent of domestic and international conflict, and the degrees of militarization across 162 independent states. The Middle East and North Africa ranked as the most violent regions and suffered the largest decline in peace over the last 8 years. Sudan and Southern Sudan were ranked at 156 (index score: 3.295 ) and 159 (index score: 3.383) respectively. This is compared to Australia, ranked ninth, with an indexed score of 1.329. In terms of peace and conflict, comparison between the 2 countries is marked and the impact of leaving difficult and turbulent situations to a more stable though unfamiliar country is a major life transition for refugees. Additionally, only I in 3 Sudanese refugees receive information about their new country of settlement prior to arrival (UNDP, 2008).

Adjusting to life in Australia can prove challenging for both Sudanese adults and children. Two thirds of Sudanese live in rural areas in Sudan, and experience a tribal based collectivist and hierarchical culture with 19 large ethnic groupings and up to 500 sub-groups (UNDP, 2008). Sudanese family structure is patriarchal in nature and women and children are actively controlled and disciplined (Tempany, 2009). Before arriving in Australia, Sudanese refugees may have already been displaced in transit countries such as Egypt or Kenya where humanitarian organizations established camps for the thousands of refugees fleeing Sudan (Hassan, 2000; Moorehead, 2002). The impact of forced migration and the conditions in refugee camps was recorded by Merffert and Marmar (2009). They recommended an urgency to address psychological wellbeing in such camps as they identified unacceptable levels of distress in the form of trauma, depression, domestic violence and community conflict.

\section{Experiencing trauma as an adult from a refugee background and the impact on their children}

Once basic needs are met, psychological wellbeing may become more pressing as individuals begin to integrate into the host society (Ingleby, 2005). Destruction of homes, internal displacement, war, assaults, rapes, killings, civil disorder and torture make up the trauma experienced by people exposed to high intensity conflict in their country of origin, (see for example, Sousa, 2014 \#233). Feeling sad, helpless, anxious, depressed, angry, and suffering with survivor guilt are common psychological reactions (GorstUnsworth \& Goldenberg, 1998; Victorian Foundation for Survivors of Torture, 1998)) and between 33$50 \%$ of individuals exposed to political violence will experience mental distress (deJong, Komproe, \& Van Ommeron, 2003; World Health Organisation, 2002). Posttraumatic stress disorder (PTSD) is routinely used to capture and/or assess such psychological reactions and manifests in the individual's behaviour with intrusive thoughts, avoidance strategies, experiencing a numbing of emotions and/or hyper-arousal (National Institute of Mental Health, 2015). PTSD impacts on functional outcome variables such as cognitive impairment, gaining and sustaining employment, establishing and maintaining social relationships, and negatively affects daily life for the individual and those around him/her. Pre-migration trauma may be carried to the host country and may be further exacerbated by post-migration acculturation difficulties. 
There are fairly consistent and strong links recorded between trauma experienced in the pre-migration phase and subsequent psychological ill health, especially with pre-migration occurrences of torture and rape (Lie, 2002). Steele, Silove, Phan, and Bauman (2002) noted that refugees who had more than 3 counts of trauma were more susceptible to mental illness and that trauma commonly was a result of not having basic needs met; for example, lack of food and water; seeing friends or family murdered, and/or being separated from family (Schweitzer, Melville, Steele, \& Lacherez, 2006).These authors point out that individuals lose a sense of self, purpose and meaning when this family separation occurs as the family unit provided emotional and psychosocial support as well as a strong sense of cultural identity. Consequently, the individual becomes more vulnerable and adjustment in a host culture more difficult both for themselves and their children and young people. The quality of care, therefore for the children and young people in their family or community can be substantially less than it would be in other circumstances.

\section{Being a child from a refugee background}

In countries where there is armed conflict, half of children die before they are five years of age. Half of children who survive have no primary school education and one third of children live in extreme poverty (UNICEF, 2009). Sexual violence, particularly targeted towards girl children and child trafficking are prevalent in countries where armed conflict persists (United Nations, 2011). Sudan itself has a young population with $41 \%$ of the population under the age of 15 (World Population Review, 2015). Sudan also has the lowest levels of education in the world with only $2 \%$ of children accessing a primary education (Victorian Foundation for Survivors of Torture, 2005). So the impact of starting school and being at school is highly unfamiliar for the majority of Sudanese refugee children.

In contrast to previous uncertainties over threats of dispersal, domicile status, and deportation as well as living in areas of armed conflict and civil war, school attendance in a country of resettlement can bring security, containment and routine as well as being a major site for socialization of children (Edgeworth, 2014; Matthews, 2008; Sidhu \& Taylor, 2009; S. Taylor \& Sidhu, 2012). However, children who have been exposed to traumatic experiences as a result of armed conflict usually demonstrate similar reactions to their adult counterparts and these may manifest themselves in the school setting. Appearing sad, withdrawn, finding it impossible to concentrate, difficult to sleep and being or appearing anxious are indicators of PTSD (M. German \& Ehntholt, 2007). This is sometimes seen when children experience difficulty in adjusting to school life, difficulties establishing peer relationships, feel isolated and find the school culture alienating (M. German, 2004).

Initiatives in the United Kingdom to deal with common PTSD behaviors for children from refugee backgrounds involved weekly group sessions led by psychologists using cognitive behavioral techniques and art/drawing therapy (Smith, Dyregrow, \& Yule, 2000). The group therapy intervention recorded a decrease in PTSD pathological symptoms (for example, recurrent thinking about traumatic events and a decrease in nightmares) (Ehntholt, Smith, \& Yule, 2005). However, there is no evidence that this type of support is commonplace in Australian contexts. Despite the difficulties and trauma, Rutter (2003) reminds us that children with refugee experiences can be very resilient and that high levels of cohesion in family groupings do predicate better learning outcomes for these children as they can adapt to the host country more easily (Montgomery, 1998). Positive adjustment is also related to arriving in the host country with both parents. The importance of family attachment and the strength of the family unit can compensate for stressful events and can provide a source of cultural capital (McMichael \& Manderson, 2004; Sonderegger, Barrett, \& Creed, 2004). So changes and threats in pre- and post- migration family structures 
are potentially deleterious for family members and negatively impact on the acculturation processes for both children and adults.

\section{Learning to speak 'Australian'}

A critical aspect of an acculturation process is linked to individuals acquiring proficiency in the language of the 'host' country (Matthews, 2008; Riggs \& Due, 2011). Developing an additional language proficiency in English for Sudanese refugees in Australia is an important skill in securing access to health services, education and employment as well as integrating and establishing social links with the host society (Poppitt \& Frey, 2007). Whilst language proficiency does not automatically include, acculturate, assimilate or create a sense of belonging for any group of students with refugee experiences, it must be recognized that without skills in formal English, chances of achieving economic independence are significantly minimized. For a Southern Sudanese population, language proficiency may be more complex as, historically, their culture is predominantly oral, making the task of becoming literate in a print based language and society particularly difficult for these groups (Burgoyne \& Hall, 2007). In 2006, the Australian Department of Immigration and Multicultural Affairs reported that $77 \%$ of individuals from refugee experiences in Queensland had little or no English language skills (cited in Milner \& Khawaja, 2010) while the Department of Immigration and Border Protection (2014) noted that a lack of such skills negatively impact on participation in social activities and community events.

Despite noting these difficulties, littleattempt was made by the decision makers and policy developers to provide appropriate language instruction (J Brown, J Miller, \& J Mitchell, 2006; Due, Riggs, \& Mandara, 2015a) with the instructors continuing to implement programs that were originally designed to accommodate the English language learning needs of migrants from vastly different backgrounds to those endured by learners with refugee experiences. The implementation of programs that reflect Tyler's four principles of curriculum that focus on the structure, grammar and vocabulary for the formal, academic use of English. There is no record of English language learning programs that stress the social and cultural conventions around language usage (see for example Street, 2003).

Exploring the insights into the multiple ways in which literacy is used in different cultural contexts, Street (2003) determined that teaching literacy in a manner which reflected only the dominant western culture and which focused on literacy as a culturally and socially neutral technical skills was not only of limited benefit to many of the participants, it also did not automatically have an impact on other aspects of development such as social and cognitive practices (Street, 2003:77). Identifying this model of teaching literacy as the 'autonomous' perspective, Street then developed a more culturally sensitive model of literacy which posited that literacy is always 'embedded in socially constructed epistemological principles' (Street, 2003:77). This perspective was identified as the 'ideological model' of literacy, which would have been a more appropriate model for these students with backgrounds of oracy, providing them with the prospect of developing language skills that would support their successful assimilation in Australian society. This approach would have facilitated authentic opportunities to explore the social and cultural potential and subtleties of language. Failure to do this impacts on the capacities of students with refugee experiences to integrate successfully which in turn is significantly linked with poor self-esteem, higher stress levels and experiencing a sub-cultural or subaltern identity The notion that being literate is not simply a matter of being able to technically communicate orally and to have sufficient language and skills to read and write fluently is a foundational tenet of Street's (2003) model of literacy as social practice and a component of Bourdieu's (1986) forms of capital. 
Both of these understandings of language and literacy have significant implications for the ways in which schools and teachers implement curricula, act as institutions of socialization and engage (Noels, Pon, \& Clement, 1996; T. Taylor \& Doherty, 2005) with the challenges of educating students with refugee experiences; either promoting or demoting acculturation. Such critical models of literacy acknowledge the social and cultural power invested in language as social practice, are more culturally sensitive and include dimensions of personal and political identity. These models are in contrast to autonomous models of literacy which simply endorse the technical aspects of reading and writing as a cognitive skills base. Autonomous approaches also surreptitiously impose Western conceptions of literacy on students who were not only from another culture but from a predominantly oral/non-print background. Dooley and Thangaperumal (2011) comment that teaching some basic skills and genre construction in the current climate of standardized national testing was necessary to some degree but they saw this autonomous pedagogical strategy as only one aspect of a productive pedagogical approach to supporting literacy competencies for children from African backgrounds.

\section{The need for re-conceptualizing current pedagogies and school practices: more than just teaching 'Australian'?}

Evidence that language remains a major obstacle for Southern Sudanese students in Australian schools is readily sourced. In the fifteen years or more years since Sudanese-Australian children started arriving in Australian schools, it appears that literacy difficulties appear to have remained relatively unchanged (J. Brown, J. Miller, \& J. Mitchell, 2006). In addition to lack of appropriate language programs and pedagogies, Matthews (2008) argues that students with refugee experiences are framed in pre-existing racialized discourses that are typical of colonial attitudes and perspectives and which produce disparaging representations of these individuals, subsequently affecting the students' educational achievement. Harris (2013) points to the negative beliefs and attitudes of some teachers have of Sudanese-Australian students in particular. One in three Sudanese-Australians reported discrimination a few times a month and experienced difficulty in securing employment because of being 'visibly different' (Colic-Peisker \& Tilbury, 2007; Murray, 2010). Australian government press and media have also contributed to negative representations of Sudanese-Australian citizens, resulting in students with refugee experiences being portrayed in ways that make acculturation and assimilation exceptionally difficult (Gatt, 2011; Kleist, 2013; Nolan, Farquharson, Politoff, \& Marjibanks, 2011; Nunn, 2010). This is in spite of Sudanese students reporting that they and their families have high aspirations to achieve academically and vocationally (Tihabano \& Schweitzer, 2007) and are positive about their potential to succeed in their new homeland.

Education, educational practices and schooling have critical roles in the social reproduction of power inequalities. In attempting to re-balance and challenge those inequalities and to undertake some new initiatives, it appears that secondary teachers and ELS teachers can act as cultural mediators in individual contexts to facilitate more authentic inclusion (Wilkinson \& Langat, 2012). Turner and Fozdar (2010) outline how young adult Southern Sudanese learners in schools were able to succeed academically and gain social and cultural capital. It appeared that 'layers' of community interaction and building positive relationships with teachers were highly influential for academic success. A community based approach was also found to have a positive impact in the Refugee Action Support Program in Greater Western Sydney (Ferfolja, 2009, Naidoo, 2012). It is unfortunate that this was not the experience of all Sudanese students in all locations. Those who attended the homework centres in Greater Western Sydney found that the friendship, interest and learning support that was lacking in their relationships with their teachers was able to be established with the student volunteers who regularly assisted them after school (Naidoo, 
2009). Typically, in a country that primarily values the white, Anglo- Saxon, middle class ways of knowing, the rich, predominantly oral linguistic culture that Sudanese children and young adults bring to their new country is rarely recognized in the Australian education system even though it has enormous potential to support their learning in English language and literacy (Cole, 2013; Major, Wilkinson, Langat, \& Santoro, 2013). Sadly, the acquisition of language competencies alone is still not a 'free pass' to inclusion, acculturation or addressing the power balance in mainstream schooling (Due, Riggs, \& Mandara, 2015b). In fact, the entire meaning of literacy and language leaning is often totally misrepresented.

As teachers, schools and education systems are so powerful in the socialization and acculturation aspirations of these students, it has been argued that schools, therefore, have the responsibility to work with students of refugee backgrounds to build community with and for them, and provide them with the critical literacy skills that will allow them to gain cultural, economic and social capital. One school took up this challenge and Hardy and Grootenboer (2013) describe a project where the school grounds were transformed into a community garden. This allowed substantial skill development for students of refugee experiences refugee and for other low SES students. It provided a context for both educational and academic outcomes to be supported. The most fertile contexts and conditions for authentically inclusive practices appear to be established through community engagement and through fostering positive teacher-student relationships. In this way a more equitable, inclusive education was able to be delivered (Cassidy \& Gow, 2005; S. Taylor \& Sidhu, 2012). Woods (2009) comments that schools are able to educate in a socially just manner, develop citizenship opportunities in the context of tolerance and be providers of wellbeing and welfare, despite the fact that not all of the teachers will engage with these ideals or are not trained to implement effective strategies to establish these outcomes themselves. However, this requires the dedication, initiative and innovation of a group of socially conscious staff members and the support of the school executive teams.

\section{Testing times: Learning to speak (and be) 'Australian' at primary school}

In terms of learning English as an additional language, the majority of research studies focus on students with refugee experiences in secondary schools, which they enter after their year of intensive English instruction outside of mainstream secondary education. There is a rather limited body of research that examines children with refugee experiences in primary school settings. These younger children are expected to readily understand western schooling, expectations, school curriculum and cultures, with very little additional, authentic support. This obviously puts them at an early disadvantage in the Australian education system compared to their English speaking peers. Riggs and Due (2011) found that there was a close connection between students' feeling of belonging, and language acquisition at primary school level. They found that for students with refugee experiences, their commitment to learning English was directly correlated to the degree to which they experienced inclusion in their school setting. The less accepted they felt, the less they engaged with English language interactions. In these and other cases, language learning could be significantly impeded by exclusionary practices such as the feelings students may have about the lack of acceptance from the host country and not being able to feel a sense of 'belonging' in relation to the majority culture (Christenson \& Havsy, 2004; McCombs, 2004; Riggs \& Due, 2011; Wilkinson \& Langat, 2012).

Keddie (2012) remarked that standardized testing in particular, was extremely problematic for this group of students, and indeed, for many other groups of students from low socio-economic and Aboriginal and Torres Strait backgrounds. She assets that it diverts teachers and teaching away from quality pedagogies 
and a focus on authentic learning. She observed that standardized testing led to bureaucratic exclusionary practices and overrode the learning needs of children who are the most vulnerable in the system. In contrast, teachers and pedagogies that consciously and actively celebrated difference, challenged the deficit view of marginalized students, including those with refugee experiences, had the potential to change a school culture and to prioritize social outcomes to provide parity participation for all students, not only those of the dominant white middle class culture. The concentrated focus on national programs of testing and attainment continues to reproduce social hierarchies that 'inferiorise' students with refugee experiences. While the Australian decision makers and policy developers may all be committed to the outcomes of the Melbourne Declaration (Ministerial Council on Education Employment Training and Youth Affairs, 2008), and may be truly interested in social justice in educational contexts; then steps need to be taken towards transforming school cultures and mandating inclusion based pedagogies and curricula that would support the educational needs of these students and other vulnerable learner groups.

\section{Testing times: teaching 'Australian' at secondary school}

The impact of inappropriate and exclusive pedagogies and curricula are equally detrimental to successful acculturation and inclusion in secondary school contexts. The Southern Sudanese students who were studied by Woods (2009), were students of secondary school age who were thought to have smaller windows of opportunity within which to become literate before leaving school and joining the workforce or proceeding to tertiary education. Despite this and the subsequent findings of the study, the pedagogical perspectives and strategies with which most secondary teachers engaged had not changed substantially, and could still negatively impact the acquisition of English language learning for these students. Dooley and Thangaperumal (2011) found that the strategies secondary teachers were using were characteristically tightly controlled, teacher directed genre approaches, emphasizing technical aspects of language rather than implementing the interactive and dialogical pedagogies that were infinitely more useful for African students with refugee experiences. Many of the teachers in these secondary settings also had difficulty regarding themselves as teachers of literacy (Dooley, 2009) as they did not teach English, but other disciplines. Situations such as this, where teachers felt it was 'not their job' added to the multiple tensions associated with the teaching of language and literacy for these students. These tensions included, (Boyd \& Myers, 1988; Mezirow, 1991; O'Sullivan, 1999) the educational system itself, the conceptual complexity of the curriculum these students were expected to access and the regimes of standardized testing, which are themselves frequently biased in content and context. All of these, in turn, still create barriers to any of these students seeking tertiary education opportunities (Fraine \& McDade, 2009).

In contrast to the pedagogical strategies that they observed in secondary classrooms, Dooley and Thangaperumal (2011) argue that vulnerable learners, including those from Southern Sudan, could benefit from the implementation of transformative pedagogical practices in the learning of literacy. These pedagogies are student centred and would empower the students to relate their learning to their own lived experiences; an approach that was found to be successful in an Australian TAFE (Technical and Further Education) context (Onsando \& Billett, 2009). Another investigation of how teachers planned for students with refugee experience to transition from language classes into mainstream classroom in Victoria also indicated the need for teachers to revisit pedagogical practices that have the potential to support the most marginalized students (Miller, Windle, \& Yazdanpanah, 2014). These strategies included planning explicit curriculum- based learning objectives and following through with appropriate strategies and resources to suit the specific learning needs of the changing cohorts. Teachers would then be able to 
work alongside the English as a Second Language (ESL) teachers in order to deliver an authentic, flexible curriculum which prioritized student learning needs.

\section{Lessons from learning to speak 'Australian' in adulthood}

Burgoyne and Hall (2007) discuss what is, in their view, the most productive way in which to teach Sudanese adults skills in language, literacy and numeracy by using highly developed informal language strategies that learners brought with them from an oracy background. These strategies included developing a flexible curriculum, so that the tasks of learning to listening, reading, speaking, writing were separated from other learning. However, this approach was heavily criticized in that the language learning was not inclusive and functional because of the recommendation that literacy and numeracy were not undertaken concurrently. They also suggested that developing language programs in collaboration with the local Sudanese community which focused on immediate resettlement or specific vocational needs; smaller class sizes; and more effective communication between teachers and training organizations regarding the students' backgrounds (Albert \& Hopkins, 2003) would be beneficial to these English learners. These recommendations were considered to be not only practical, but beneficial in terms of improved learning outcomes for the adults and therefore for the children. Burgoyne and Hall (2007) also decried the 'autonomous' approach which is characterized by the use if decontextualized words, learning the alphabet and other highly abstract strategies commonly used in Western literacy pedagogies as unsuitable activities for these students; as were the use of texts that were unrelated to their experiences, everyday lives and interests. However, any programs that were overly focused on short term objectives and which did not have sufficient concurrent emphasis on numeracy could easily disadvantage these learners, not only as students and workers themselves but as the carers and primary educators of their children, especially in the absence of effective support from community organizations.

\section{Educational partnerships in literacy acquisition that failed to deliver}

Part of the government's approach to meeting the substantial needs of students with refugee backgrounds resulted in the partnership of schools with community organizations in an attempt to provide a holistic approach to the educational and acculturation needs of these students (Sidhu \& Taylor, 2009). While these partnerships offered multiple opportunities to strengthen educational prospects, most especially for students at risk, the potential to make a significant contribution to schools and students was marred by a highly competitive contractual procedure. As a result, the agencies with whom the educational partnerships' decision makers decided to work, offered services that represented the best value for money and were adept at supporting English speaking students with special needs rather than supporting those at risk who had no English as a basis from which to proceed. While teachers and schools welcomed the partnerships, there were a number of problematic issues, many of which were focused around the issue of inadequate resourcing. This emphasis on fiscal conservatism, risk management and accountability was more influential in the establishment of these partnership programmes than the mission of welfare support and advocating for social justice (Sidhu \& Taylor, 2009:669). Matthews (2008) comments that these piecemeal partnerships have characterized Australian educational attempts to prepare students with refugee experiences forthe Australian educational system and the competencies they needed in literacy to achieve in an Australian test based school system.

\section{Pre-service teachers delivering 'Australian': doing it better?}


As previously indicated, students and their families who have refugee experiences regard education as an important avenue through which to improve their lives and prospects (Tihabano \& Schweitzer, 2007). The positive outcomes noted by Naidoo (2009) as a result of the interactions between secondary students with an African refugee background (many of whom were Sudanese) with secondary pre-service teacher volunteers in the homework centre already discussed, included more than the friendships developed; they were also positively linked with a positive change in student linguistic capital (Bourdieu). The student volunteers also experienced positive outcomes. They developed useful professional teaching skills as a result of the reciprocal learning setting. As a result, this partnership was mutually valuable, especially in the context of the distinct literacy problems associated with an orally based language (Ferfolja, 2009). It is hopeful that these preservice teachers are permitted to enrich the educational contexts in which they are employed to become the types of teachers who are ethical and equitable in their pedagogical perspectives and practices. However, these pre service volunteers also serve to highlight the situation of the majority of in service teachers who have not had the opportunities to develop these skills and are not adequately prepared with the pedagogies or perspectives that enable them to become successful teachers of students with diverse cultural and socio- economic backgrounds. As noted by Woods, (2009) many teachers do not know, refuse to acknowledge the value of, or do not have the personal capacity to engage with alternative pedagogies that empower their students (Kahn, 2009). This is hardly surprising as, as the time of writing only 10 of the Australian universities offering preservice teacher education preparation have dedicated, mandatory courses in their preservice education programs to educate students teachers about the development of critical cultural skills and the teaching of English competencies for English language learners. As a result, colonial attitudes of superiority may found amongst some groups of teachers. This, in turn, is exacerbated by pedagogical, assessment and accountability schedules of neoliberalism which currently influence Australian educational policies and practices with the consequence that marginal groups of many descriptions are actively discriminated against in Australian educational contexts.

\section{In-service teachers: struggling to 'Australianize' students with refugee experiences?}

In this current climate of neoliberal political principles which is dominating all levels of education in Australia, teachers face many competing demands in their workplace, including the delivery of highly advertised and high stakes standardized testing results, namely the National Assessment Program of Literacy and Numeracy (NAPLAN). This national testing regime, a cornerstone of the economy- dominated education system, is considered extremely high stakes for schools, students and their communities because of the development of a public website maintained by the government which advertises these results and facilitates the comparison of schools, one to another. (It also provides evidence of the ways in which the Aboriginal and Torres Strait Islander students significantly underachieve on this type of testing compared to their non-Indigenous counterparts.) This, and the steady, substantial promotion of transmission type pedagogies have taken precedence over one of the most basic purposes of education; which may be understood as ensuring that all students are given opportunities to become successful learners. This situation is evidenced at the classroom level as vulnerable English Language Learners, most specifically students with refugee experiences from backgrounds of oracy, are presented with a curriculum from which it is difficult for them to make meaning and implemented in ways that do not accommodate either their learning needs or their traditional learning strengths. The introduction of NAPLAN testing has led to considerable changes in the ways teachers are regarded as professionals, has served to impact conservatively on their pedagogical perspectives and theory, and has frequently 
diminished their sense of responsibility towards accommodating student diversity and difference in learning contexts. Ultimately, the model of neoliberalism which has impacted on an already colonial perspective of what it is to educate and be educated, has served to produce a teaching and learning culture which promotes achievement as competition, instead of communities of learners (Burgh, Field, \& Freakley, 2005) who respect and celebrate diversity whilst acknowledging commonalities (Atasay, 2015).

DiscussionThe lack of appropriate supporting structures and the involvement of poorly - prepared, piecemeal educational partnerships, has assigned teachers in Australia the responsibility of acculturating and teaching these vulnerable groups of students without a national strategy for competently educating at least one subaltern group: the group of Sudanese-Australians that increased in size by a staggering 288\% between 2001 and 2005 (United Nations, 2011). Historically, the only guidance was to be found in the ways in which Australia had previously educated people of colour: by disregarding their cultural and social perspectives and regarding them as 'deficit' in relation to the white middle class Anglo - Saxon culture whose perspectives were perpetuated in educational system. These circumstances have resulted in an urgent need for policy development and progressive planning across several levels of the education system. These policies do not only need to provide for the assessment of problems, the management of student learning and the monitoring of student progress at a whole school level of accountability, including organizational procedures, structures and pedagogy and curriculum development (Matthews, 2008). They also need to support the effective transformation of what it means to be an educator in Australia. This transformation necessitates a shift from the exclusive value attributed to current discourse of power to the celebration of the potential and possibilities of embracing many ways of knowing and of making meaning. All of this requires substantial leadership, scholarship and courage. It also requires commitment, both fiscal and philosophical, and a focus on social equity. This needs not only to be evidenced in the policy documents, the curriculum, the preparation of preservice teachers but also in the ongoing professional learning opportunities for in service teachers and in the implementation of pedagogical strategies, attitudes and values that transform (Harrell-Levy \& Kerpelman, 2010; Levitt, 2008; O'Sullivan, 1999; Onsando \& Billett, 2009; Ukpokodu, 2009a, 2009b; Willink). The following recommendations details suggestions for polic reform across 4 levels - pre-service training, qualified teachers, executive leadership and regulatory and credentialing bodies.

\section{Recommendations}

All preservice teachers need to have opportunities to engage in mandatory coursework that specifically examines the sociocultural perspectives of literacy and numeracy, multiple ways of knowing and the potential of authentically transformative pedagogies in real classroom contexts. In this way they can develop strategies for introducing students to English literacy practices whilst acknowledging and respecting their traditional ways of knowing and the relative strengths these students bring to the learning contexts These programs also need to provide opportunities for preservice teachers to have professional experiences in classrooms where students with refugee experiences are placed, Additionally, all preservice teachers need to develop cultural sensitivity, preferably in informal, regular contexts that are designed to support students with refugee experiences, which can then be investigated further in their coursework. They also need preparation programs that are specifically formulated in terms of social justice, reflection and ethical decision making which may require specialist professional learning in the above areas of study so that they develop the capacities, attitudes and perspectives that are necessary for them to mentor beginning teachers into socially just teaching and learning spaces and critically appraise the depth to which beginning teachers are able to build positive, supportive relationship with all 
students, including those from diverse backgrounds such as those with refugee experiences from various places of the conflict and custom.

Those who develop curricula for such diverse populations as those in Australian classroom are ethically required to challenge the legacy of 'Tylerism' (Tyler, 1949) and the impact that this economy based model of teaching and learning and its subsequent variations (see New South Wales Department of Education and Training, 2003; Newmann \& Associates, 1996; Wiggins \& Mc Tighe, 2005; Wiggins \& McTighe, 2007), has had on Australian curriculum development and implementation as a direct result of both Tyler's (1949) original model and the neoliberal agenda which has impacted heavily on educational systems in Australia in much the same way as it has in other "western ' countries (de Lissovey, 2013; de Lissovy, 2015; Endcott et al., 2015; Saltman, 2003; Saltman \& Means). As a result, education in Australia is currently characterised by constant competition, provision of public education as a so called 'even playing field' dominated by explicit teaching, an increasing focus on predetermined learning outcomes and the abandonment of the 'losers' in these educational battlefields as unproductive and unnecessary in society. The situation of students with refugee experiences such as those from Southern Sudan is further complicated by the 'violence' (Anwaruddin, 2016) that is inflicted upon them as students whose traditional culture and prior educational experiences are far removed from the schooling in which they participate in their new homeland, specifically in the context of their English language learning. A socially just Australian curriculum would be one that acknowledges all students in the teaching and learning process; not just as a vehicle for the input- output of content knowledge, but as individuals, as developing humans whose cognitive work is to be celebrated as diverse, individual, meaningful and valuable as personal capital and not simply as an economic resource for those powerful individuals and organisations whose agenda is being served by the current model of educational curriculum, policy, compliance and accountability that is Australian education.

To become effectively and authentically committed to playing a role in improving the lives and prospects of students with refugee experiences, executive leadership teams will require particular sensitivities in newly defined areas of educational policy, purpose and focus so they may effectively support the staff, students and communities in their care. Of particular importance will be the prolonged engagement with professional learning that focusses explicitly on the development of leadership qualities that facilitate whole school approaches to inclusion, belonging and respect of difference, both in the means by which the curriculum is implemented in classrooms and in the ethos or hidden curriculum. The policy makers and credentialing bodies also have a powerful responsibility to Australian society. These responsibilities include making clear policy statements about the multiple purposes of education in Australia as a clear and socially just response to the diverse populations that comprise the clients of Australian education. These are fiscal responsibilities in addition to philosophical, social and psychological concerns and considerations. Any reform in Australian education cannot proceed without policy to guide and inform those who are engaged at the school, community and classroom levels in its most practical application. It is therefore recommended that credentialing bodies support the professional learning of teachers who work in schools with populations of students with refugee experience. Similarly, institutions that provide any level of preservice preparation programs for teachers must be directed and financed to provide the professional learning outlined above as mandatory for teacher registration in Australia and essential for the health of the educational system and those for whom it seeks to provide formal educational opportunities for learning. In order to earn the multicultural status that is so frequently associated with Australian society, further recommendations can be made. School communities could be provided with 
language specialists and counselling support staff who are experts in the area of the impact of trauma on identity, social interaction, emotion and cognition. A similar support system to that provided in English educational contexts see (Smith et al., 2000: Ehntholt, Smith \& Yule, 2005) would appear to beneficial in Australian contexts also. The provision of specifically trained aides in classrooms to support teaching and learning also needs to be provided, with a focus on encouraging members of the subaltern groups and those with refugee experiences to prepare to undertake these roles themselves and also to be prepared as teachers in order to meet the needs of students with multiple ways of learning and knowing.

\section{Conclusion}

This retrospective review of the literature relating to some of the most traumatized students (and most visible) from refugee experiences illustrates the neoliberal mindset of the educational policymakers and decision makers. Groups of these students with refugee experiences, including those from Southern Sudan, have many cultural and societal characteristics in common with the Aboriginal and Torres Strait Islander students whose ways of knowing, cultural practices and traditions, learning preferences and difficulties with traditional British based educational strategies are well researched and documented. Both groups are highly visible by their colour, both have strong, rich cultural traditions in art, storytelling, music and poetry in addition to having backgrounds of oracy. However, the literature discussed reveals that the learning needs of these students with refugee experiences were not only largely unmet, but that superficial and naïve assumptions dominated the educational provisions that were provided for them. Issues of culture and tradition were largely ignored in the educational processes, despite the exceedingly adverse circumstances endured by these students and what remained of their families. Consequently, what was publicly and politically understood to be a humane, generous gesture on behalf of the Australian Government in welcoming these families and communities into a new homeland could be criticized as a decision for which the educational community was unprepared, despite educational interaction with the Indigenous communities of Australia, many of whom have similar cultural characteristics. The critique provided by this review signals an underlying malaise of Australian education in general; the lack of capacity to embrace diversity, the influence of neoliberal economic model and the absence of a system and structure that empowers all students to contribute meaningfully to Australian society; a situation that continues as increasing numbers of students with refugee experiences continue to arrive in the country.

While the reflection, the discussion and the literature presented in this review may be considered problematic in that it all conformed to Western research tradition and interpretation (Darder, 2015); it may be some time before Australian educational policy makers and practitioners are able to engage with research conducted by the Southern Sudanese groups themselves. In the meantime, the acknowledgement of schooling as the primary agent of acculturalization for students of refugee experience makes this review relevant and timely, as increasing numbers of students with diverse background but common refugee experiences make their way into Australian schools.

\section{References}

Albert, M., \& Hopkins, A. (2003). Building Bridges between Academics and Service Providers to Sudanese Refugees in Australia. The Australasian Review Of African Studies, 25(2), 99. 
Anwaruddin, S. (2016). Contesting the violence of Tylerism: toward a cosmopolitan approach to the curriculum of second language teacher education. Teaching in Higher Education, 29(4), 429-441. doi:DOI: 10.1080/13562517.2016.1155550

Atasay, E. (2015). Neoliberal Multiculturalism Embedded in Social Justice Education: Commodification of Multicultural Education for the 21st Century. Journal for Critiacl Education, 12(3), 171- 205.

Bird, G. (1995). Power, Politics and the Location of "The Other" in Multicultural Australia.

Multiculturalism and the law. Retrieved from

http://www.aic.gov.au/media_library/conferences/multiculturalism/bird.pdf

Bourdieu, P. (1986). The forms of capital. In J. G. Richardson (Ed.), Handbook of theory and research for the theory of education (pp. 46-58). New Yok: Greenwood.

Boyd, R., \& Myers, J. (1988). Transformative education. Internationsl Journal; of Lifelong Education, 7(4), 261-284.

Brown, J., Miller, J., \& Mitchell, J. (2006). Interrupted schooling and the acquisition of literacy : experiences of Sudanese refugees in Victorian secondary schools. . . Australian Journal of Language and Literacy;, 29(2), 150-162.

Brown, J., Miller, J., \& Mitchell, J. (2006). Interrupted schooling and the acquisition of literacy: Experiences of Sudanese refugees in Victorian secondary schools. Australian Journal of Language and Literacy, 29(2), 150-162.

Burgh, G., Field, T., \& Freakley, M. (2005). Ethics and the Community of Enquiry: An approach to ethics education. Melbourne: Thomson Social Science Press.

Burgoyne, U., \& Hall, O. (2007). Classroom management stategies to address the needs of Sudanese refugee learners. Adelaide, SA: National Centre for Vocational Education Research.

Cassidy, E., \& Gow, G. (2005). Making up for lost time : the experiences of Southern Sudanese young refugees in high schools. . Youth Studies Australia,, 24(3), 51-55.

Christenson, S., \& Havsy, L. (2004). Family, school, peer relationships: significance for social, emotional and academic learning. In J. Zins, R. Weissberg, M. Wang, \& H. Walberg (Eds.), Buildinbg academic success on social and emotional learning (pp. 59-75). New York: Teachers College Press.

Cole, D. (2013). Deleuze and narrative investigation: the multiple literacies of Sudanese families in Australia. . Literacy, 47(1), 35-41.

Colic-Peisker, V., \& Tilbury, F. (2007). Integration into the Australian labour market: The experience of three 'visibly different' groups of recently arrived refugees. International Migration, 45, 59-83.

Darder, A. (2015). Decolonizing Interpretive Research: A critical bicultural methodology for social change. The International Education Journal: Comparative Perspectives, 14(2), 63-77.

Davidson, G., \& Carr, S. (2010). Forced migration, social exclusion and poverty: Introduction. Journal of Pacific Rim Psychology, 4(1), 1-6.

Davidson, G., Murray, K., \& Schweitzer, R. (2008). Review of refugee mental health assessment: Best practices and recommendations. Journal of Pacific Rim Psychology, 4, 72-85.

de Lissovey, N. (2013). Pedagogy of the impossible: neoliberalisom and the ideology of accountability. Policy Futires in Education, 11(4), 423-435. doi:http://dx, doi.org/10.2304/pfie.2013.11.4.423

de Lissovy, N. (2015). Education and Emancipation in the Neoliberal Era: being, tecahing and power. New York: Palgrave Macmillan.

deJong, J., Komproe, I., \& Van Ommeron, M. (2003). Common mental disorders in postconflict settings. Lancet, 361(9375), 2128-2130.

Dooley, K. (2009). Rethinking pedagogy for middle school students with little or no severely interrupted schooling. English Teaching: Practice and Critique, 8(1), 5-22. 
Dooley, K., \& Thangaperumal, P. (2011). Pedagogy and participation: literacy education for low literate refugee students of African origin in a western school system. Language and Education, 25(5), 385-397.

Due, C., Riggs, D., \& Mandara, M. (2015a). Educators' experiences of working in Intensive English Language Programs: The strengths and challenges of specialised English language classrooms for students with migrant and refugee backgrounds. Australian Journal of Education, 59(2), 169181. doi:10.1177/0004944115587365

Due, C., Riggs, D., \& Mandara, M. (2015b). Educators' experiences of working in Intensive English Language Programs: The strengths and challenges of specialised English language classrooms for students with migrant and refugee backgrounds. Australian Journal Of Education 59(2), 169181.

Edgeworth, K. (2014). Black bodies, white rural spaces: disturbing practices of unbelonging fo 'refugee' students. Critical Studies in Education. doi:10.1080/17508487.2014.956133

Ehntholt, K., Smith, P., \& Yule, W. (2005). School-based cognitive-behavioural therapy group intervention for refugee children who have experienced war-related trauma. Clinical Child Psychology and Psychiatry, 10(2), 235-250.

Endcott, J., Wright, G., Goering, C., Collet, V., Jenny, G., \& Davs, J. (2015). Robots teaching other little robots: Neoliberalism, CCSS and teacher professionalism. The Review of Education, Pedagogy and Cultural Studies, 37, 414-447.

Ferfolja, T. (2009). The Refugee Action Support program: developing an understanding of diversity. Teaching Education, 20(4), 395-407.

Fraine, N., \& McDade, R. ( 2009). Reducing bias in psychometric assessment of culturally and linguistically diverse students fom refugee backgrounds in Australian schools: A process approach. Australian Psychologist, 44(1), 16-26.

Gatt, K. (2011). Sudanese refugees in Victoria: An analysis of their treatment by the Australian govenment. International Journal of Comparative and Applied Criminal Justice, 35(3), 207-219.

German, M. (2004). Working with Somali boys in a secondary school: An educating experience. In P. Travers \& g. Klein (Eds.), Equal Measures: Ethnic Minority and Bilingual Pupils in Secondary Schools (pp. 65-77). Stoke-on-Trent: Stoke-on-Trent.

German, M., \& Ehntholt, K. (2007). Working with refugee children and families. The Psychologist, 20(3), 152-155.

Ghosh, F. (2005). Reduced Economic Benefit to the Refugees: Missing Recognition? Aalborg, DK: Aalborg University.

Gorst-Unsworth, C., \& Goldenberg, E. (1998). Psychological sequelae of torture and organised violence suffered by refuges from Iraq. . British Journal of Psychiatry, 172, 90-94.

Hardy, I., \& Grootenboer, P. (2013). Schools, teachers and community: cultivating the coindfitions for engaged student learning. Curriculum Studies, 45(5), 697-719.

Harrell-Levy, M., \& Kerpelman, J. (2010). Identity Process and Transformative Pedagogy: Teachers as Agents of Identity Formation. Identity, 10(2), 76-91. doi:10.1080/15283481003711684

Harris, A. (2013). In Transit/ion: Sudanese Students' Resettlement, Pedagogy and Material Conditions. Journal Of Pedagogy, 4(1), 79-97.

Hassan, A. (2000). Sudanese Refugees: Down and Out in Cairo. Retrieved from http://www.worldpress.org/mideast/312.cfm

Ingleby, D. (2005). Forced Migration and Mental Health: Re-thinking the care of refugees and displaced persons. New York Springer.

Institute for Economics and Peace. (2015). Global Peace Index: Measuring Peace, its Causes and its Economic Value. In I. f. E. a. Peace (Ed.). Sydney: Institute for Economics and Peace. 
Kahn, R. (2009). Towards Ecopedagogy: Weaving a broad based pedagogy of liberation for animals, nature and the oppressed people of the earth. In A. Darder, M. Baltodarno, \& R. Torres (Eds.), The Critical Pedagogy Reader (pp. 522-540). New York: Routledge.

Keddie, A. (2012). Pursuing justice for refugee students: addressing issues of cultural (mis) recognition. International Journal of Inclusive Education, 16(12), 1295-1310.

Kleist, J. (2013). Remembering for refugees in Australia: political memories and concepts of democracy in refugee advocacy post Tampa

Journal of Intercultural Studies, 34(6), 665-683.

Levitt, R. (2008). Freedom and Empowerment: A Transformative Pedagogy of Educational Reform. Educational Studies, 44(1), 47-61. doi:10.1080/00131940802225085

Lie, B. (2002). A 3-year follow-up study of psychosocial functioning and general symptoms in settled refugees. Acta Psychiatrica Scandinavica, 106, 415-425.

Major, J., Wilkinson, J., Langat, K., \& Santoro, N. (2013). Sudanese young people of refugee background in rural and regional Australia: Social capital and education success. Australian and International Journal of Rural Education, 23(3), 95-105.

Matthews, J. (2008). Schooling and settlement: refugee education in Australia. International studies in sociology of education, 18(1), 38-45.

McCombs, B. (2004). The Learner-Centered Psychological Principles: A framework for Balancing Academic Achievement and Social-Emotional Learning Outcomes. In J. Zins, R. Weissberg, M. Wang, \& H. Walberg (Eds.), Building Academic Success on Social and Emotional Learning (pp. 2339). New York: Teachers College Record Press.

McMichael, C., \& Manderson, L. (2004). Somali women and well-being: Social networks and social capital among immigrant women in Australia. Human Organisation,, 63, 88-90.

Merffert, S., \& Marmar, C. (2009). Drafur refugees in Cairo: Mental health and interpersonal conflict in the aftermath of genocide. . Journal of Interpersonal Violence,, 24(1835-1848).

Mezirow, J. (1991). Transformative dimensions of adult learning. San Francisco: Jossey - Bass.

Miller, J., Windle, J., \& Yazdanpanah, L. (2014). Planning lessons for refugee background students: challenges and strategies. International Journal of Pedagogies \& Learning, 9(1), 38-48.

Milner, K., \& Khawaja, N. (2010). Sudanese refugees in Australia: the impact of acculturation stress. Journal of Pacific Rim Psychology,, 4(1), 19-29.

Ministerial Council on Education Employment Training and Youth Affairs. (2008). Melbourne Declaration on Educational Goals for Young Australians.

Montgomery, E. (1998). Refugee children from the Middle East. Scandinavian Journal of Social Medicine Supplement, 54, 1-152.

Moorehead, C. (2002). Suspended in Cairo. Retrieved from https://www.opendemocracy.net/people/article 287.jsp

Murray, K. (2010). Sudanese perspectives on resettlement in Australia. Journal of Pacific Rim Psychology, $4(1), 30-45$.

Naidoo, L. (2009). Developing social inclusion in after school homework tutoring: A study of African refugee students in Greater Western Sydney British Journal of Sociology of Education, 30(3), 261-273.

National Institute of Mental Health. (2015). What is Post-traumatic Stress Disorder? . Retrieved from http://www.nimh.nih.gov/health/topics/post-traumatic-stress-disorder-ptsd/index.shtml

New South Wales Department of Education and Training. (2003). Quality Teaching. Sydney: NSW Department of Education and Training.

Newmann, F., \& Associates. (1996). Authentic achievement: Restructuring schools for intellectual qulaity. San Francisco: Jossey - Bass. 
Noels, K., Pon, G., \& Clement, R. (1996). Language, identity and adjustment: The role of linguistic selfconfidence in the acculturation process. Journal of Language and Social Psychology,, 15, 246264.

Nolan, D., Farquharson, K., Politoff, V., \& Marjibanks, T. (2011). Mediated multiculturism: Newspaper representations of Sudanese migrants in Australia. Jouirnal of Intercultural Studies, 32(6), 655671.

Nunn, C. (2010). Spaces to speak: challenging representations of Sudanese Australians. Journal of Intercultural Studies, 31(2), 183-198.

O'Sullivan, E. (1999). Transformative learning: educational vision for the 21st century. London: Zed.

Onsando, G., \& Billett, S. (2009). African Students from Refugee Backgrounds in Australian TAFE Institutes: A Case for Transformative Learning Goals and Processes. International Journal of Training Research, 7(2), 80-94.

Poppitt, G., \& Frey, R. (2007). Sudanese adolescent refugees: Acculturation and acculturation stress. Australian Journal of Guidance and Counselling, 17, 160-181.

Protection, D. o. I. a. B. (2014). The Place of Migrants in Contemporary Australia: A Summary Report. Canberra: The Australian Government.

Riggs, D., \& Due, C. (2011). (Un)common ground?: English language acquisition and experiences of exclusion amongst new arrival students in South Australian primary schools. Global Studies in Cultue and Power, 18(3), 273-290.

Rutter, J. (2003). Supporting Refugee Children in 21st Century Britain: A Compendium of Essential Information. . Stoke-on-Trent: : Trentham Books.

Sales, R. (1992). The deserving and the undeserving? Refugees, asylum seekers and welfare in Britain. Critical Social Policy,, 22, 456-478.

Saltman, K. (2003). Education as Enforcement: Militarization and Corporatization of Schools. In K. Saltman \& D. Gabbard (Eds.), Education as Enforcement: Militarization and Corporatization of Schools (pp. 1-19). NY: Routledge.

Saltman, K., \& Means, A. Students as Critical Citizens/Educated Subjects but Not as Commodities/Tested ObjectsThe Sage Guide to Curriculum n Education (pp. 284-).

Schweitzer, R., Melville, F., Steele, Z., \& Lacherez, P. (2006). Trauma, post-migration living difficulties, and social support as predictors of psychological adjustment in resettled Sudanese refugees. . Australian and New Zealand Journal of Psychiatry,, 40, 179-187.

Sidhu, R., \& Taylor, S. (2009). The trials and tribulations of partnerships in refugee settlement services in Australia. Journal of Education Policy, 24(6), 655-672.

Smith, P., Dyregrow, A., \& Yule, W. (2000). Children and War: Teaching Recovery Techniques. Bergen, Norway:: Foundation for Children and War.

Sonderegger, R., Barrett, P., \& Creed, P. (2004). Models of cultural adjustment for child and adolescent migrants to Australia: A population based study. . Journal of Child and Family Studies,, 13, 357371.

Steele, Z., Silove, D., Phan, T., \& Bauman, A. (2002). Long term effect of psychological trauma on the mental health of Vietnamese refugees settled in Australia: A population based study. The Lancet, 306(1056-1067).

Street, B. (2003). What's 'New' in New literacy studies:?: Critical appoaches to theory and practice. Current Issues in Comparative Education, 5(2), 77 -91.

Taylor, S., \& Sidhu, R. (2012). Supporting refugee students in schgools: what constitutes inclusive practice? International Jouranal of Inclusive Education, 16(1), 39-56.

Taylor, T., \& Doherty, A. (2005). Adolescent sport, recreation and physical education: Experiences of recent arrivals to Canada. . Sport, Education and Society,, 10(2), 211-238. 
Tempany, M. (2009). What research tells us about the mental health and social wellbeing of Sudanese refugees: a literature review. . Transcultural Psychiatry,, 46, 300-315.

Tihabano, K., \& Schweitzer, R. (2007). A qualitative study of the career aspirations of resettled young Sudanese and Somali refugees. Journal of Psychology in Africa, 17(1-2), 13-21.

Turner, M., \& Fozdar, F. (2010). Negotiating 'Community' in Educational Settings: Adult South Sudanese Students in Australia Journal of Intercultural Studies, 31(4), 363-382.

Tyler, R. (1949). Basic Principles of Curriculum and Instruction. Chicago: Chcaogo Unversity Ptess.

Ukpokodu, O. (2009a). Pedagogies that Foster Transformative Learning in a Multicultural Education Course: a Reflection. Journal of Praxis in Multicultural Education, 4(1), 1-8. Journal of Praxis in Multicultural Education, 4(1), 1-8.

Ukpokodu, O. (2009b). The Practice of Transformative Pedagogy. Journal on Excellence on College Teaching, 20(2), 43-67.

UNICEF. (2009). The State of the World's Children. . Retrieved from http://www.unicef.org/sowc09/report/report.php

United Nations. (2011). Office of the Special Representative of the Secretary-General for Children and Armed Conflict: Strategic Framework, 2011-2013. . United Nations.

United Nations Development Program. (2009). Human Development Reports: 2007/8 Reports. New York, NY: United Nations Development Program

Victorian Foundation for Survivors of Torture. (1998). Rebuilding Shattered Lives. . Melbourne: Victorian Foundation for Survivors of Torture.

Wiggins, G., \& Mc Tighe, J. (2005). Understanding by Design. Alexandria, VA: Association for Supervision and Curriculum Development.

Wiggins, G., \& McTighe, J. (2007). Schooling by Design: Mission, Action and Achievements. Alexandria VA: Association for Supervision Curriculum Development.

Wilkinson, J., \& Langat, K. (2012). Exploring educators' practices for African students from refugee backgrounds in an Australian regional high school The Australasian Review Of African Studies, 33(2), 158-177.

Willink, K. G. Teaching for change : articulating, profiling, and assessing transformative learning throught communicative capabilities / Kate G. Willink \& Jeanne M. Jacobs. [Thousand Oaks, Calif.] Sage Publications.

Woods, A. (2009). Learning to be literate: Issues of pedagogy for recently arrived refugee youth in Australia. Critical Inquiry in Language Studies, 6(1-2), 81-101. doi:10.1080/15427580802679468

World Health Organisation. (2002). World Report on Violence and Health. . Geneva.: WHO.

World Population Review. (2015). Sudan Population 2015. . Retrieved from http://worldpopulationreview.com/countries/sudan-population/ 